\title{
Sleep in children with cerebral palsy
}

\section{Serebral palsili çocuklarda uyku}

\author{
Erkan MESCi ${ }^{1}$, Afitap içAĞASIOĞLU ${ }^{1}$, Yasemin YUMUŞAKHUYLU ${ }^{1}$, Nilgün MESCi ${ }^{2}$, Sadiye MURAT ${ }^{1}$
}

SUMMARY

Cerebral palsy (CP) is a neurological disorder that is frequently associated with sleep disorders. Despite this, causes of sleep disorders among children with $\mathrm{CP}$ and the association of sleep disorders with motor capacity and severity of disease have not been fully elucidated. In the current study, we aimed to explore the association of sleep problems with factors including disease severity and motor capacity and the effects of sleep impairment on quality of life of children with CP. For this study, we enrolled 76 children with SP with an age range of 4-14 years. For all patients, the Gross Motor Function Scale (GMFS)-88 was used to evaluate functional motor capacity, the Pediatric Quality of Life Inventory (PedsQL) to assess the quality of life and the Pediatric Sleep Questionnaire (PSQ) to assess sleep problems. Classification of gross motor functions of the patients was performed using the Gross Motor Function Classification System (GMFSC). GMFSC Level 1 and 2 patients were considered as mild, Level 3 patients as moderate and Level 4 and 5 patients as having severe $C P$. PSQ scores were found to be lower in the mild CP group compared with those in moderate and severe CP groups $(p=0.005$ and $p=0.000$, respectively). PSQ scores were negatively correlated with PedsQL and GMFS scores (for all $p<0.001$ ). Given the substantial loss of quality of life caused by sleep disorders, sleep problems should be taken into account when establishing treatment strategies for children with $C P$, particularly for those with severe motor disabilities.

\section{ÖZET}

Serebral palsi (SP) beraberinde sıklıkla uyku bozuklukları görülen bir nörolojik tablodur. Buna rağmen, SP'li çocuklarda uyku bozukluklarının nedenleri, motor kapasite ve hastalık şiddeti ile ilişkisi tam olarak bilinmemektedir. Bu çalışmada, serebral palsili çocuklarda uyku sorunlarının hastalık şiddeti, motor kapasite gibi faktörlerle ilişkisini ve yaşam kalitesi üzerine etkilerini araştırmayı amaçladık. Çalışmaya yaşları 4-14 yıl aralığında olan 76 SP'li çocuk alındı. Hastaların Kaba Motor Fonksiyon Ölçeği-88 (KMFÖ) ile motor fonksiyonel kapasiteleri, Çocuklar Için Yaşam Kalitesi Ölçeği (ÇiYKÖ) ile yaşam kaliteleri, Çocuklarda Uyku Ölçeği (ÇUÖ) ile uyku sorunları değerlendirildi. Hastaların kaba motor sınıflamaları Kaba Motor Fonksiyon Sınıflama Sistemi (KMFSS) ile yapıldı. KMFSS 1 ve 2 olanlar hafif, 3 olanlar orta, 4-5 olanlar ise ağır SP olarak kabul edildi. ÇUÖ skorlarının hafif SP grubunda orta ve ağır SP gruplarına göre düşük olduğu görüldü (sırasıyla $p=0,005$, $p=0,000)$. ÇUÖ skorlarının ÇiYKÖ ve KMFÖ skorları ile negatif ilişkili olduğu saptandı (tüm p'ler<0,001). Ağır motor disabilitesi olanlar başta olmak üzere, SP'li çocuklarda tedavi stratejileri belirlenirken, ciddi yaşam kalitesi kayıplarına yol açan uyku bozuklukları göz ardı edilmemelidir.

\section{GíRiş}

Serebral palsi (SP), gelişimini sürdürmekte olan beyinde, ilerleyici olmayan bir hasara bağlı olarak gelişen kalıcı hareket, postür ve tonus bozukluğu olarak tanımlanmaktadır ${ }^{1}$.

Ülkemizde SP sıklığı, 1000 canlı doğumda 4,4 olarak bildirilmiştir². Temel öğesi motor fonksiyon bozuk- luğu olmakla birlikte, tabloya sıklıkla davranış bozuklukları, öğrenme güçlüğü, duyusal sorunlar ve konuşma bozuklukları da eşlik etmektedir ${ }^{1}$. Bunlar dışında epilepsi, solunum sorunları, görme ve işitme bozuklukları, ağız ve diş sorunları, iskelet anomalileri, gelişim geriliği gibi eşlik eden sorunlar da hastalığın tedavisini güçleştirmektedir.

Normal büyüme ve gelişme gösteren çocuklarda \%5

Received: 28.08.2015

Accepted: 11.09 .2015

${ }^{1}$ Medeniyet Üniversitesi Göztepe Eğitim ve Araştırma Hastanesi, Fizik Tedavi ve Rehabilitasyon Kliniği

${ }^{2}$ Haydarpaşa Numune Eğitim ve Araştırma Hastanesi, Fizik Tedavi ve Rehabilitasyon Kliniği

Yazışma adresi: Dr. Erkan Mesci, Galipbey Cad. Meşe Sok. No:1/19, Küçükyalı-Maltepe-İstanbul

e-mail: erkanmesci@hotmail.com 
civarında uyku bozukluğu görülmesine rağmen, SP'li çocuklarda çok daha yüksek oranlarda uyku sorunu olduğu gösterilmiştir ${ }^{3}$. Bu çocuklarda uykuyu başlatma ve devam ettirebilmede yetersizlik, düzensiz uykuuyanıklık geçişleri, uyku ile ilişkili solunum güçlükleri ve artmış gün içi uyku hâli olduğu bilinmektedir.

SP'li çocuklar gerek mevcut primer beyin hasarı, gerekse hastalığa eşlik eden sorunlar nedeni ile uyku bozukluğu gelişimi için çok sayıda risk faktörüne sahiptirler. Epilepsi ${ }^{5}$, görme bozukluklari ${ }^{4}$, mental gerilik $^{5}$, spastisite ve ağrı ${ }^{6}$, solunum sorunları ${ }^{7}$, yatak içinde dönme güçlüğü 6 gibi sorunlar SP'de uyku bozuklukları ile ilişkilendirilmektedir. Obstrüktif uyku apnesinin SP'de çok sık görüldüğü ve bunun olasılıkla solunumun merkezinin kontrolü ile üst solunum yolları kas tonusunun normal olmamasına bağlı olduğu bildirilmektedir ${ }^{7}$. SP'de uyku sorunlarına spina bifida ve müsküler distrofilere göre daha sık rastlandığı gösterilmiştir 6 .

Yapılan sınırlı sayıdaki çalışmada, SP'li çocuklarda uyku bozukluklarının gerek çocuğun gerekse ailesinin yaşam kalitesinde bozulmaya yol açtığı saptanmıştır ${ }^{4,8}$.

Özellikle son yıllarda yapılan az sayıda çalışmada, konu ile ilgili bazı bilgilere ulaşılabilmiş olsa da, SP'li çocuklarda uyku bozukluklarının nedenleri, motor kapasite ve hastalık şiddeti ile ilişkisi, kesin olarak ortaya konabilmiş değildir.

Bu çalışmada; serebral palsili çocuklarda uyku sorunlarının hastalık şiddeti, motor kapasite gibi faktörlerle ilişkisini ve yaşam kalitesi üzerine etkisini araştırmayı amaçladık.

\section{GEREÇ ve YÖNTEM}

Bu çalışma, hastanemiz fizik tedavi ve rehabilitasyon kliniği bünyesindeki serebral palsi polikliniğinde takip edilmekte olan 76 SP'li çocuk üzerinde yapıldı. ÇaIışma öncesinde hastanemizin lokal Etik Kurulunun onayı alındı. Çalışmaya velileri bilgilendirilmiş yazılı onam vererek çalışmaya katılmayı kabul eden çocuklar alındı. Hasta popülasyonu 4-14 yaşlar arasındaki, diyabet, malignite, ağır kardiyak ve pulmoner hastalığı olmayan çocuklar olarak belirlendi.

Çocukların yaş, cinsiyet gibi demografik özellikleri ile epilepsi, görme bozukluğu, solunum sorunu gibi eşlik eden durumlar kaydedildi. Çalışmaya alınan çocuklar, genel nörolojik ve kas iskelet sistemi muayenelerinin ardından serebral palsi tipi ve spastisite açısından değerlendirildiler. Spastik SP'li çocuklar, etkilenen vücut bölgelerine göre; hemiplejik, diplejik, triplejik ve quadriplejik olarak sınıflandırıldı.

Tüm çocukların Kaba Motor Fonksiyon Sınıflama Sistemi (KMFSS) kullanılarak kaba motor fonksiyon seviyeleri değerlendirildi. KMFSS oturma, yer değiştirme ve hareketlilik temelinde çocuğun kendi başlattığı hareketleri esas alan bir değerlendirme sistemidir ${ }^{9}$. Beş seviyeli sınıflama sisteminde seviyeleri tanımlarken temel kriter, aralarındaki farkların günlük yaşamda anlamlı olmasıdır. Seviyeler genel başlıkları ile değerlendirildiğinde: Seviye 1. Kısıtlama olmaksızın yürür, Seviye 2. Kısıtlamalarla yürür, Seviye 3. Elle tutulan hareketlilik araçlarını kullanarak yürür, Seviye 4. Kendi kendine hareket sınırlanmıştır. Motorlu hareketlilik aracını kullanabilir. Seviye 5. Elle itilen bir tekerlekli sandalyede taşınır. KMFSS'nin genişletilmiş ve yeniden düzenlenmiş versiyonunun Türkçe güvenilirlik çalışması El ve ark. tarafından yapılmıştır ${ }^{10}$.

Çocukların kaba motor fonksiyon becerileri Kaba Motor Fonksiyon Ölçeği-88 (KMFÖ) kullanılarak değerlendirildi. KMFÖ SP'li çocukların kaba motor fonksiyonları gerçekleştirebilme kapasitesi ve limitasyonlarını değerlendiren, zaman içinde meydana gelen değişimleri ölçmeye olanak sağlayacak şekilde standardize edilmiş bir testtir ${ }^{11}$. KMFÖ ile beş ayrı bölümde toplam 88 madde değerlendirilmektedir. Yatma-yuvarlanma bölümünde ${ }^{17}$, oturma bölümünde $^{20}$, emekleme-dizüstü bölümünde ${ }^{14}$, ayakta durma bölümünde ${ }^{13}$ ve yürüme-koşma-merdiven çıkma bölümünde 24 madde bulunmaktadır. Her madde Likert skalasına göre değerlendirilir. Aktivite başlatılamıyorsa 0 , bağımsız başlatılıyorsa 1 , kısmen tamamlanıyorsa 2, bağımsız tamamlanıyorsa 3 puan verilir. Her maddeden alınan puanlar toplanarak elde edilen to- 
tal skor değerlendirilmeye alınır.

SP'li çocuklarda uyku bozukluklarının değerlendirilmesi Çocuklarda Uyku Ölçeği (ÇUÖ) kullanılarak yapıldı. ÇUÖ Chervin ve ark. ${ }^{12}$ tarafından özellikle uyku ile ilgili solunum sorunlarını değerlendirmek için geliştirilmiştir. Ölçeğin 22 soruluk kısa ve 72 soruluk uzun versiyonu bulunmaktadır. Bu çalışmada, ölçeğin Türkçe geçerlilik ve güvenilirlik çalışması yapılmış olan uzun versiyonu kullanılmıştır ${ }^{12}$. Ölçek üç bölümden oluşmaktadır. A bölümünde (Gece ve uyku zamanı olan davranışlar) 43, B bölümünde (Gün içerisindeki davranışlar ve olası sorunlar) 23, C bölümünde (Dikkat eksikliği ve hiperaktivite) 6 soru yer almaktadır. A ve B bölümündeki sorular "evet", "hayır", "bilmiyorum", C bölümündeki sorular ise dörtlü Likert ölçeği şeklinde yanıtlanmaktadır. Ölçeğin puanlanmasında 22 soru kullanılmaktadır. Uzun versiyon içerdiği açık uçlu sorular sayesinde uykunun niteliksel olarak da incelenmesini sağlamaktadır. Çalışma içinde ölçeğin toplam puanı değerlendirmeye alınmıştır. Uyku bozukluğu tanısı için ölçek toplam skorunda kesim noktası 6 olarak alınmıştır ${ }^{12}$.

Hastalarda yaşam kalitesi değerlendirilmesi Çocuklar İçin Yaşam Kalitesi Ölçeği (ÇiYKÖ) ile yapıldı. Bu ölçek 2-18 yaşları arasındaki çocuk ve ergenlerin yaşam kalitelerini ölçmek için geliştirilmiştir. Orijinal adı Pediatric Quality of Life Inventory (PedsQL) olan ölçeğin Türkçe geçerlilik ve güvenilirlik çalışması Çakın ve ark. tarafından yapılmıştır ${ }^{13}$. Çalışmada, ölçeğin 2-4, 5-7, 8-12 ve 13-18 yaş formları kullanıldı. Ölçek 5 seçenekli Likert tipi ölçek şeklinde geliştirilmiştir. Çocuk formlarında yanıt üç seçeneklidir. Sorunun yanıtı hiçbir zaman olarak işaretlenmişse 100, ender olarak olarak işaretlenmişse 75 , bazen olarak işaretlenmişse 50 , sıklıkla olarak işaretlenmişse 25 , hemen her zaman olarak işaretlenmişse 0 puan verilir. Skor hesaplanırken yanıtlanan tüm soruların puanları toplanıp, işaretlenen soru sayısına bölünmektedir. Ölçeğin toplam puanı dışında, fiziksel sağlık toplam puanı ile emosyonel işlevsellik, sosyal işlevsellik ve okul işlevsellik puanlarının birlikte değerlendirilmesinden elde edilen psikososyal sağlık toplam puanı gibi alt ölçekleri bulunmaktadır ${ }^{13}$. Çalışmada ölçeğin toplam puanı değerlendirmeye alındı.

SP'li çocukların genel nörolojik ve kas iskelet sistemi muayeneleri ile spesifik fonksiyonel değerlendirmeleri pediatrik rehabilitasyon konusunda deneyimli fiziatrist tarafından yapıldı. Uyku bozuklukları üzerine SP şiddetinin etkisini değerlendirebilmek amacı ile hastalar KMFSS seviyelerine göre hafif, orta ve ağır olarak sınıflandırıldı. KMFSS seviyesi 1 ve 2 olan çocuklar hafif, KMFSS seviyesi 3 olan çocuklar orta, KMFSS seviyesi 4 ve 5 olan çocuklar ise ağır SP olarak kabul edildi ${ }^{14}$.

\section{İstatistiksel analizler}

Çalışmada elde edilen bulgular değerlendirilirken, istatistiksel analizler için SPSS (Statistical Package for Social Sciences) for Windows 19.0 programı kullanıldı. Çalışma verileri değerlendirilirken tanımlayıcı istatistiksel metod olarak normal dağılım gösteren veriler için ortalama ve standart sapma, normal dağılım göstermeyen veriler için medyan ve minimummaksimum değerleri kullanıldı. Normal dağılım göstermeyen niceliksel verilerin hafif, orta, ağır SP grupları arası karşılaştırmaları için Kruskal-Wallis testi kullanıldı. Ikili karşılaştırmalar Mann-Whitney $U$ testi ile yapıldı ve Bonferroni düzeltmesi kullanılarak yorumlandı. Uyku ölçeği skorları ile KMFSS, KMFÖ, ÇіYKÖ skorları arasındaki korelasyon analizleri Spearman Korelasyon Testi ile yapıldı. Sonuçlar \%95'lik güven aralığında, anlamlılık $p<0.05$ düzeyinde değerlendirildi.

\section{BULGULAR}

Çalışma sonunda değerlendirmeye alınan 76 çocuğun yaş ortalaması $6,7 \pm 2,6$ yıl idi. Çocukların 37 'si $(\% 48,7)$ kız, 39'u (\%51,3) erkekti. SP'li çocuklar klinik tiplerine göre sınıflandırıldığında $47(\% 61,8)$ spastik diplejik, 6 $(\% 7,9)$ spastik hemiplejik, $2(\% 2,6)$ spastik triplejik, 18 $(\% 23,7)$ spastik quadriplejik, $3(\% 3,9)$ diskinetik hasta olduğu görüldü. KMFSS'ye göre hastaların dağılımı ve uyku bozuklukları ile ilişkili olabilecek eşlik eden sorunların görülme sıklıkları Tablo 1'de görülmektedir. 
KMFSS seviyelerine göre yapılan sınıflandırma sonucunda 24 (\%31,6) hastanın hafif (grup 1), 31 (\%40,8) hastanın orta (grup 2) , $21(\% 27,6)$ hastanın ise ağır (grup 3) SP'li grupta yer aldığı görüldü. Çocuklarda uyku ölçeği skorlarının gruplar arasında anlamlı düzeyde farklı olduğu saptandı $(p=0,000)$. Yapılan ikili karşılaştırmalar sonucunda grup $1^{\prime}$ in ÇUÖ ortanca skorunun, gerek grup 2, gerekse grup 3'e göre belirgin şekilde düşük olduğu görüldü (sırası ile $p=0,005$, $p=0,000$ ). Yine grup 2'nin ÇUÖ skoru da grup 3'e göre anlamlı olacak şekilde düşük bulundu (Tablo 2).

Tablo 1. Serebral palsili çocukların karakteristik özellikleri.

\begin{tabular}{|c|c|c|}
\hline & \multicolumn{2}{|c|}{ Serebral Palsi } \\
\hline & $\mathbf{n}$ & $\%$ \\
\hline \multicolumn{3}{|l|}{ Klinik tip } \\
\hline Spastik diplejik & 47 & 61.8 \\
\hline Spastik hemiplejik & 6 & 7.9 \\
\hline Spastik triplejik & 2 & 2.6 \\
\hline Spastik quadriplejik & 18 & 23.7 \\
\hline Diskinetik & 3 & 3.9 \\
\hline Toplam & 76 & 100 \\
\hline \multicolumn{3}{|c|}{ Kaba motor fonksiyon sınıflama sistemi } \\
\hline 1 & 8 & 10.5 \\
\hline II & 16 & 21.1 \\
\hline III & 31 & 40.8 \\
\hline IV & 9 & 11.8 \\
\hline V & 12 & 15.8 \\
\hline Toplam & 76 & 100 \\
\hline Uyku Bozukluğu & 28 & 36.8 \\
\hline Epilepsi & 18 & 23.7 \\
\hline Mental Retardasyon & 23 & 30.3 \\
\hline Görme Bozukluğu & 18 & 23.7 \\
\hline Konuşma Bozukluğu & 27 & 35.5 \\
\hline İnkontinans & 20 & 26.3 \\
\hline
\end{tabular}

KMFÖ skorları açısından üç grubun birbirinden farklı olduğu saptandı $(p=0,000)$. İkili grup karşılaştırmaları sonucunda grup 1'in KMFÖ skorlarının grup 2 ve grup 3 'ten istatistiksel olarak ileri düzeyde anlamlı olacak şekilde yüksek olduğu görüldü (tüm p'ler=0,000). Grup 2'nin KMFÖ skoru da grup 3'e göre belirgin şekilde yüksekti ( $p=0,000)$ (Tablo 2 ).

Üç grubun ÇiYKÖ skorları arasında da anlamlı düzeyde fark olduğu gözlendi $(p=0,000)$. İkili karşılaştırmalarda grup 1'in ÇiYKÖ skorlarının grup 2 ve grup 3'e göre belirgin şekilde yüksek olduğu saptandı (tüm $\left.p^{\prime} l e r=0,000\right)$. Aynı şekilde grup 2'nin ÇiYKÖ skoru da grup 3'e göre ileri düzeyde anlamlı şekilde yüksekti $(p=0,000)$ (Tablo 2).

Uyku bozukluğu saptanan hastalar arasında konuş-

Tablo 3. Uyku ölçeği skorları ve ilişkili faktörlerin korelasyon tablosu.

\begin{tabular}{llllll}
\hline & & \multicolumn{1}{c}{ ÇUÖ } & KMFÖ & çіYKÖ & KMFSS \\
\hline ÇUÖ & $\mathrm{r}$ & 1,000 &,- 546 &,- 635 &, 640 \\
& $\mathrm{p}$ & &, $000^{*}$ &, $000^{*}$ &, $000^{*}$ \\
KMFÖ & $\mathrm{r}$ &,- 546 & 1,000 &, 871 &,- 856 \\
& $\mathrm{p}$ &, $000^{*}$ & &, $000^{*}$ &, $000^{*}$ \\
ÇIYKÖ & $\mathrm{r}$ &,- 635 &, 871 & 1,000 &,- 842 \\
& $\mathrm{p}$ &, $000^{*}$ &, $000^{*}$ & &, $000^{*}$ \\
KMFSS & $\mathrm{r}$ &, 640 &,- 856 &,- 842 & 1,000 \\
& $\mathrm{p}$ &, $000^{*}$ &, $000^{*}$ &, $000^{*}$ &, $000^{*}$
\end{tabular}

*p<0,001, r: korelasyon katsayısı, ÇiYKÖ: çocuklar için yaşam kalitesi ölçeği, ÇUÖ: çocuklarda uyku ölçeği, KMFÖ: kaba motor fonksiyon ölçeği, KMFSS: kaba motor fonksiyon sınıflama sistemi.

Tablo 2. Çocuklarda uyku ölçeği, kaba motor fonksiyon ölçeği ve çocuklar için yaşam kalitesi ölçeği skorlarının hafif-orta-ağır SP grupları arasında karşılaştırılması.

\begin{tabular}{|c|c|c|}
\hline Gruplar & Medyan (Min-max) & P değeri* \\
\hline Çocuklarda uyku ölçeği & & $0,005^{*}$ \\
\hline Grup 1-grup 2 & $2(0-9)-4(1-9)$ & $0,000 * *$ \\
\hline Grup 1-grup 3 & $2(0-9)-7(2-11)$ & $0,001^{*}$ \\
\hline Grup 2-grup 3 & $4(1-9)-7(2-11)$ & \\
\hline Kaba motor fonksiyon ölçeği & & $0,000 * *$ \\
\hline Grup 1-grup 2 & $242(158-264)-175(38-262)$ & $0,000 * *$ \\
\hline Grup 1-grup 3 & $242(158-264)-10(0-123)$ & $0,000 * *$ \\
\hline Grup 2-grup 3 & $175(38-262)-10(0-123)$ & \\
\hline Çocuklar için yaşam kalitesi ölçeği & & $0,000 * *$ \\
\hline Grup 1-grup 2 & $67,5(44,6-90)-51,4(18,1-64)$ & $0,000 * *$ \\
\hline Grup 1-grup 3 & $67,5(44,6-90)-19(0-40,6)$ & $0,000^{*}$ \\
\hline Grup 2-grup 3 & $51,4(18,1-64)-19(0-40,6)$ & \\
\hline
\end{tabular}

*Mann- Whitney U testi, *p<0,01, **p<0,001 
ma sorunu bulunan hasta sayısının anlamlı şekilde daha fazla olduğu görüldü $(p=0,002)$. Benzer şekilde mental retardasyon ve görme sorunu sıklığı da uyku bozukluğu saptanan hastalarda daha yüksekti (sırası ile $p=0,003, p=0,024)$. Bununla birlikte, uyku sorunu olan hastalarda epilepsisi olan hasta sayısı uyku sorunu olmayanlardan farklı değildi $(p=0,614)$.

ÇUÖ ile KMFÖ ve ÇiYKÖ arasında ileri düzeyde anlamIı negatif ilişki $(p<0,001)$, KMFSS ile yine ileri düzeyde anlamlı pozitif ilişki $(p<0,001)$ olduğu görüldü. Çocuklarda Uyku Ölçeği skorları ve diğer faktörlerin birbirleri ile olan ilişkileri tablo 3'te görülmektedir.

\section{TARTIŞMA}

SP'li çocuklarda artmış uyku sorunları sıklığı yapılan pek çok çalışma ile ortaya konulmuştur ${ }^{5,6}$. Çalışmamızda, saptadığımız \%36,8'lik uyku bozukluğu görülme oranı literatür ile karşılaştırılabilir düzeydedir. Adiga ve ark. ${ }^{15}$ hastalarının \%36'sında patolojik sınırda uyku skoru bildirmişlerdir. Romeo ve ark. ${ }^{5}$ göre SP'li çocukların \%40'ında en az bir uyku patolojisi mevcuttur. Yine Romeo ve ark. ${ }^{16}$ tarafından yapılan bir başka çalışmada, 3-5 yaşları arasındaki SP'lerde uyku bozukluğu sıklığının \%30 olduğu gösterilmiştir. Hemmingsson ve ark. ${ }^{6}$ ise aralarında SP'nin de bulunduğu fiziksel disabiliteye yol açan hastalığı olan bir grup çocuğun \%48'inde uyku bozukluğu olduğunu bildirmişlerdir. Newman ve ark. ${ }^{3}$ SP'li çocukların \%23'ünde patolojik düzeyde total uyku skoru, \%44'ünde en az bir klinik uyku sorunu saptamışlardır. Literatür genel olarak değerlendirildiğinde SP'li çocukların yaklaşık \%33'ünün uyku bozukluklarından etkilendiği bildirilmektedir ${ }^{17}$.

Bulgularımız farklı motor disabilite düzeylerine sahip çocuklarda uyku ölçeği skorları arasında belirgin farklar olduğu yönündedir. Hafif SP grubunun uyku ölçeği skorları orta ve ağır SP gruplarından daha düşük bulunmuştur. Yapılan korelasyon analizlerinde de buna paralel olarak KMFSS ve KMFÖ skorları ile ÇUÖ skoru arasında belirgin negatif ilişki gözlenmiştir. Newman ve ark. ${ }^{3}$ göre motor disabilitenin şiddeti uyku bozukluğu gelişimini etkileyen bir faktördür. Bu çalışmada, spastik quadriplejik ve diskinetik SP'li çocuklarda uyku patolojilerine daha sık rastlandığı gösterilmiştir. Çalışmamızda da uyku patolojisi saptanan hastaların çoğunlukla ağır motor sorunları olan quadriplejik çocuklar olduğu gözlenmiştir. Romeo ve ark. ${ }^{5}$ diskinetik tip SP ve KMFSS seviye 5 ile uyku patolojileri arasında ilişki saptamışlardır. Elsayed ve ark. ${ }^{18}$ tarafından yapılan bir çalışmada da en sık saptanan uyku patolojisinin uyku ile ilişkili solunum sorunları olduğu ve bunun en sık KMFSS seviye 4 ve 5 olan çocuklarda görüldüğü bildirilmiştir.

Çalışmamızda uyku bozukluğu görülen çocuklarda epilepsi oranı uyku bozukluğu olmayanlardan farkIı bulunmadı. Romeo ve ark. ${ }^{5}$ göre epilepsi ile SP'de uyku bozuklukları arasında ilişki mevcuttur. Newman ve ark. ${ }^{3}$ yalnızca aktif epilepsi ile uyku bozuklukları arasında ilişki olduğunu bildirmişlerdir. Bu çalışmada, aktif epilepsili çocuklarda saptanan uyku bozukluğu tipi artmış gün içi uyku hâlidir. Adiga ve ark. $\mathrm{da}^{15}$ total uyku skorlarının nöbet geçirme ile ilişkili bulunduğunu bildirmişlerdir. Bu çalışmada, nöbet geçirmeyen epilepsili çocuklarda gün içi somnolansa rastlanmamıştır. Çalışmamızda nöbet geçiren aktif epilepsili hasta bulunmamaktadır. Wayte ve ark.'da7 uyku sorunları ile epilepsi arasında ilişki saptayamadıklarını bildirmişlerdir. Antiepileptik ilaçların uyku bozuklukları ile ilişkili olduğu yönünde bulgular mevcuttur. Ancak bazı araştırmalarda bu ilişki gösterilememiştir ${ }^{3}$.

Görme bozukluklarıSP'li çocuklarda uyku sorunu riskini artıran önemli bir faktör olarak ele alınmaktadır ${ }^{3,4,7}$. Çalışmamızda da uyku sorunu görülen çocuklarda görme bozukluğu olan hasta sayısının daha yüksek olduğu saptanmıştır. Görme sorunlarının uyku üzerine olumsuz etkisinin uyku-uyanıklık siklusunu düzenleyen melatonin hormonunun salınımında oluşan düzensizliğe bağlı olduğu düşünülmektedir ${ }^{7}$.

Uyku sorunu olan hastalarımızda konuşma bozukluğu ve mental retardasyon sıklığının yüksekliği de literatür ile uyumludur. SP'li çocuklarda uyku bozuklukları ile mental sorunların ilişkisi bilinen bir gerçektir ${ }^{5}$. Gelişen uyku sorunların ikincil olarak kognitif ve emosyonel sorunlara yol açarak kısır bir döngü oluşturabi- 
leceği bildirilmektedir ${ }^{19}$.

Bulgularımız uyku ölçeği skoru arttıkça hastaların yaşam kalitelerinin düştüğünü göstermektedir. Zuculo ve ark.'nın ${ }^{8}$ 4-18 yaş arası SP'li çocuklar üzerinde yaptıkları çalışmanın sonuçları bunu desteklemektedir. Sandella ve ark.'da ${ }^{20}$ çalışmamızda olduğu gibi düşük yaşam kalitesi ile uyku bozuklukları ve KMFSS arasında ilişki olduğunu göstermişlerdir. SP'li çocuklarda uyku bozukluklarının gün içi aktiviteleri ve okul performansını olumsuz etkilediği bilinmektedir ${ }^{7}$. Üstelik SP'li çocuklarda uyku bozukluklarının yalnızca çocukların değil ebeveynlerinin de günlük yaşamını ve psikolojik durumlarını etkilediği gösterilmiştir ${ }^{4}$.

SP'li çocuklarda uyku bozukluklarının erken tanısı önemlidir. Öyle görünmektedir ki uyku bozuklukları, primer santral sinir sistemi patolojisi zemininde komorbid sorunların katkısı ile oluşmaktadır. Literatüre göre SP'li çocuklarda, uyku bozukluklarının düzeltilmesi için geliştirilmiş spesifik bir yöntem bulunmamaktadır ${ }^{21}$. Bu nedenle uyku sorununa zemin hazırlayan komorbid durumların tedavisi önem kazanmaktadır. Örneğin, obstrüktif uyku apnesi tedavisinde gastroözofageal reflü, hipersalivasyon ve obezite gibi komorbid durumların erken dönemde tedavisi önemli katkılar sağlamaktadır ${ }^{7}$. Ayrıca yatak ve diğer uyku materyallerinin seçimi, uygun çevre ISISI, çevrede televizyon ve bilgisayar gibi cihazların olmaması, pencereleri izolasyonu gibi non-farmakolojik yöntemlerin önemine dikkat çekilmektedir ${ }^{19}$.

Çalışmamızın limitasyonları arasında; uyku bozukluğu tanısının anket ile konulması, kontrol grubunun olmaması ve çalışmanın kesitsel dizayn edilmiş olması sayılabilir. Uyku patolojileri ile ilgili çalışmalar, polisomnografi'nin pahalı ve zor ulaşılabilir olması nedeni ile genellikle anketler ile yapılmaktadır. SP'de uyku sorunları nedenlerinin bulunması ve uygun tedavilerin geliştirilebilmesi için, tanıda objektif yöntemlerin kullanıldığı çalışmalara gereksinim bulunmaktadır.

Sonuç olarak, KMFSS seviyesi yüksek, tüm vücut tutulumlu, fonksiyonel kapasitesi düşük, komorbid sorunları fazla olan hastalarda belirgin olmak üzere SP'li çocuklarda uyku bozukluğu gelişme riskinin yüksek olduğu unutulmamalıdır. Primer nörolojik tablo ve eşlik eden sorunlar nedeni ile, ciddi morbidite yaşayan SP'li çocukların uykularının rahatlatılabilmesi, onları yeni kognitif, emosyonel ve fiziksel problemlerden koruyabileceği gibi, gerek kendilerinin, gerekse ebeveynlerinin yaşam kalitelerine katkı sağlayacaktır.

\section{KAYNAKLAR}

1. Rosenbaum P, Paneth N, Leviton A, et al. A report: the definition and classification of cerebral palsy. Dev Med Child Neurol Suppl 2007; 109: 8-14.

2. Serdaroğlu A, Cansu A, Özkan S, et al. Prevalence of cerebral palsy in Turkish children between the ages of 2 and 16 years. Dev Med Child Neurol 2006; 48: 413-416.

http://dx.doi.org/10.1111/j.1469-8749.2006.tb01288.x

3. Newman CJ, O'Regan M, Hensey O. Sleep disorders in children with cerebral palsy. Dev Med Child Neurol 2006; 48: 564568.

http://dx.doi.org/10.1017/S0012162206001198

4. Wayte S, McCaughey E, Holley S, et al. Sleep problems in children with cerebral palsy and their relationship with maternal sleep and depression. Acta Paediatrica 2012; 101: 618-623. http://dx.doi.org/10.1111/j.1651-2227.2012.02603.x

5. Romeo DM, Brogna C, Quintiliani M, et al. Sleep disorders in children with cerebral palsy: neurodevelopmental and behavioral correlates. Sleep Medicine 2014; 15: 213-218. http://dx.doi.org/10.1016/j.sleep.2013.08.793

6. Hemmingsson H, Stenhammar AM, Paulsson K. Sleep problems and the need for parental night-time attention in children with physical disabilities. Child: care, health and development 2008; 35: 89-95.

http://dx.doi.org/10.1111/j.1365-2214.2008.00907.x

7. Tremblay ES, Constantin E, Gruber R, et al. Sleep in children with cerebral palsy: A review. Journal of Child Neurology 2011; 26: 1303-1310.

http://dx.doi.org/10.1177/0883073811408902

8. Zuculo GM, Knap CCF, Pinato L. Correlation between sleep and quality of life in cerebral palsy. CoDAS 2014; 26: 447-456. http://dx.doi.org/10.1590/2317-1782/20140201435

9. Palisano R, Rosenbaum P, Walter S. Development and reliability of a system to classify gross motor function in children with cerebral palsy. Dev Med Child Neurol 1997; 39: 214-223. http://dx.doi.org/10.1111/j.1469-8749.1997.tb07414.x

10. El O, Baydar M, Berk $\mathrm{H}$, et al. Interobserver reliability of the Turkish version of the expanded and revised gross motor function classification classification system. Disabil Rehabil 2012; 34: 1030-1033.

http://dx.doi.org/10.3109/09638288.2011.632466

11. Russell P, Rosenbaum PM, Avery L, et al. Gross motor function measure (GMFM-66\&GMFM-88) user's manual. Cambridge University Press, 2002: 1-24.

12. Öner $P$, Barut $Y$, Öner Ö, ve ark. Çocuklarda uyku ölçeği'nin geçerlik ve güvenirliği. Klinik Psikofarmakoloji Bülteni 2009; 19: 382-395. 
13. Memik ÇK, Ağaoğlu $B$, Coşkun $A$, ve ark. Çocuklar için yaşam kalitesi ölçeğinin 8-12 yaş çocuk formunun geçerlik ve güvenirliği. Çocuk ve Gençlik Ruh Sağlığı Dergisi 2008; 15: 87-98.

14. Harries N, Kassirer M, Amichai T, et al. Changes over years in gross motor function of 3-8 year old children with cerebral palsy using the gross motor function measure [GMFM-88]. IMAJ 2004; 6: 408-411.

15. Adiga D, Gupta A, Khanna M, et al. Sleep disorders in children with cerebral palsy and its correlation with sleep disturbance in primary caregivers and other associated factors. Ann Indian Acad Neurol 2014; 17: 473-476. http://dx.doi.org/10.4103/0972-2327.144044

16. Romeo DM, Brogna C, Musto E, et al. Sleep disturbances in preschool age children with cerebral palsy: a questionnaire study. Sleep Medicine 2014; 15: 1089-1093. http://dx.doi.org/10.1016/j.sleep.2014.05.008

17. Galland BC, Elder DE, Taylor BJ. Interventions with a sleep outcome for children with cerebral palsy or a post-traumatic brain injury: a systematic review. Sleep Med Rev 2012; 16:
561-573.

http://dx.doi.org/10.1016/j.smrv.2012.01.007

18. Elsayed RM, Hasanein BM, Sayyah HE, et al. Sleep assessment of children with cerebral palsy: Using validated sleep questionnaire. Ann Indian Acad Neurol 2013; 16: 62-65. http://dx.doi.org/10.4103/0972-2327.107708

19. Dutt R, Roduta-Roberts $M$, Brown CA. Sleep and children with cerebral palsy: A review of current evidence and environmental non-pharmacological interventions. Children 2015; 2: 78-88. http://dx.doi.org/10.3390/children2010078

20. Sandella DE, O'Brien LM, Shank LK, et al. Sleep and quality of life in children with cerebral palsy. Sleep Med 2011; 12: 252-256. http://dx.doi.org/10.1016/j.sleep.2010.07.019

21. Angriman $M$, Caravale $B$, Novelli $L$, et al. Sleep in children with neurodevelopmental disabilities. Neuropediatrics 2015; 46: 199-210.

http://dx.doi.org/10.1055/s-0035-1550151 